\title{
Simulation of large-scale energy storage to improve high-voltage DC stability
}

\author{
Guoxin $\mathrm{He}^{1, *}$, Hongshui $\mathrm{Lu}^{1}$, Dongmei Yang ${ }^{1}$, Yonghua Chen ${ }^{1}$ and Wei $\mathrm{Du}^{1}$ \\ ${ }^{1}$ NARI Group Corporation, NARI Research Institute, 211106 Nanjing, China
}

\begin{abstract}
Study on large-scale electrochemical energy storage simulation is carried out in this paper to discuss its feasibility in enhancing the stability of HVDC power transmission, thus providing a reference for large-scale energy storage planning and design in the background of global energy internet. The paper introduces the development status quo of the large-scale energy storage technology, and provides an analysis of the active and inactive power features after HVDC commutation failure by establishing a largescale energy storage model and a HVDC power transmission system commutation failure model, thereby exploring the configuration feasibility of the large-scale energy storage technology; Then, a simulation analysis is given on the effect of large-scale energy storage on HVDC power transmission fault features; Finally, a prospect was expected towards the application tendency of large-scale energy storage in global energy internet.
\end{abstract}

\section{Introduction}

The growth of global energy consumption remains strong. As is predicted by International Energy Agency (IEA), the demand for global energy will grow by $30 \%$ as of 2040 [1]. In face of the sustainable challenge of insufficient resources, environmental pollution climate change and development imbalance, constructing global energy internet is considered an innovative solution which aims at creating an energy union as well as a fate union of humans [2]. In September 2015, Chinese president Xi Jinping delivered an important speech in the UN Development Summit. He advocated constructing global energy internet to meet global electronic needs in a clean and green manner, which received strong reaction and support by relevant parties of the UN. Taking superhigh voltage power system as the backbone grid, global energy internet will be used as a foundation platform to support the large-scale development, transmission and use of clean energy worldwide. Energy storage technology, as a flexible energy adjustment resource, requires certain configuration for key links of global energy internet such as electricity generation, power transmission and distribution and power utilization. It is developing in a direction of higher capacity, lower costs and more greening. The large-scale energy storage technology specific to the global energy internet mainly includes pumped storage, compressed air energy storage, electrochemical energy storage, heat storage and hydrogen storage [3]. In recent years, extensive concern has been received from all sectors of society on using large-scale electrochemical energy storage technology to meet the urgent need of peak and frequency modulation during power transmission and distribution. For this, some scholars have proposed to carry out energy storage system planning by taking active power and inactive power features of extra-high voltage circuits into comprehensive consideration [4-5].

According to the national GB51048-2014 criteria, large electrochemical energy storage power stations are defined to have the power of $30 \mathrm{MW}$ and the capacity of $30 \mathrm{MWh}$ [6-7]. In fact, large-scale electrochemical energy storage applications with the power high than $100 \mathrm{MW}$ or the capacity higher than MWh have become available at home and abroad. For instance, the $101 \mathrm{MW} / 202 \mathrm{MWh}$ energy storage power station in Zhenjiang, Jiangsu, which was put into practice in July, 2018 represents a typical application scene of energy storage technology in power system. Nonetheless, large-scale electrochemical energy storage system integration and application is still confronted with multiple challenges such as the lack of refined planning and design, significant decline of battery pack performance, risk of fires, loss of stability by multimachine energy storage converters in parallel, risk of DC system fault and obvious customization needs for the energy management system [8-10].

Study on large-scale electrochemical energy storage simulation is carried out in this paper to discuss its feasibility in enhancing the stability of HVDC power transmission, thus providing a reference for large-scale energy storage planning and design in the background of global energy internet. The paper is divided into four parts. The first part introduces the development status quo of the large-scale energy storage technology; the second part provides an analysis of the active and inactive power features after HVDC commutation failure by establishing a large-scale energy storage model and a HVDC power transmission system commutation failure

\footnotetext{
* Corresponding author: heguoxin@sgepri.sgcc.com.cn
} 
model, thereby exploring the configuration feasibility of the large-scale energy storage technology; in the third part, a simulation analysis is given on the effect of largescale energy storage on HVDC power transmission fault features; finally, a prospect was expected towards the application tendency of large-scale energy storage in global energy internet.

\subsection{Large-scale energy storage technology}

\subsubsection{Technical comparison}

In power systems, a main approach to improve the HVDC operation stability is by installing inactive power compensation devices which can be divided into passive devices and active devices. Power capacitors belong to the former, while SVC, STATCOM and synchronous compensators belong to the latter. With the function of active and inactive output, electrochemical energy storage can realize charging and discharging within $200 \mathrm{~ms}$, thus, it is recognized as an emerging technology supporting the stable operation of HVDC network [8-11].

Currently, large-scale electrochemical energy storage technology is mainly applied to the following three contexts [12-13]: large-scale comprehensive services; frequency modulation; and power transmission and distribution network services. The power cost and the energy cost of large-scale integrated electrochemical energy storage technology in different contexts are shown in Figure 1 and Figure 2 respectively.

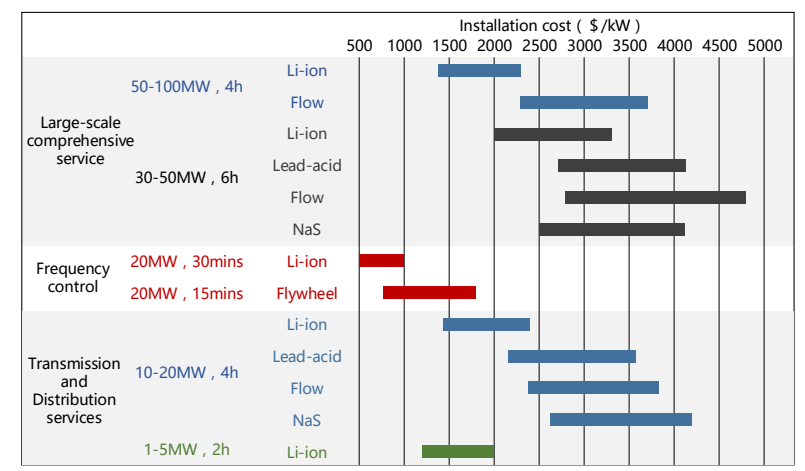

Fig. 1. Power cost of typical electrochemical energy storage.

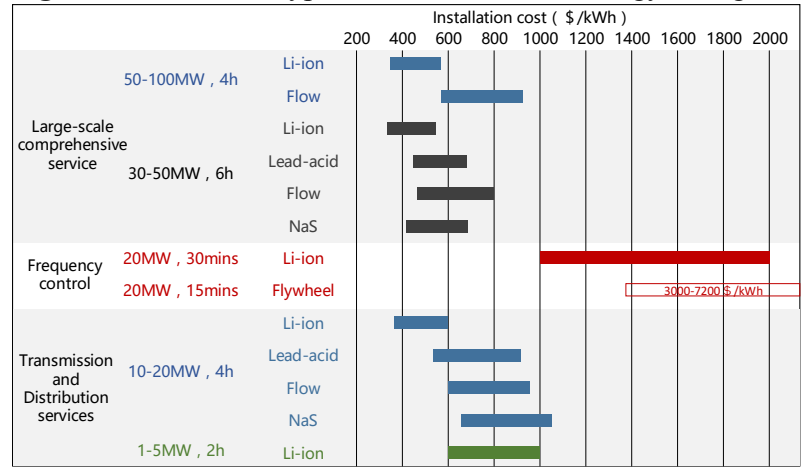

Fig. 2. Energy cost of typical electrochemical energy storage.

Seen from the figures, lithium-ion batteries enjoy obvious cost advantage no matter in which large-scale application context. It is because compared with other types of batteries like liquid flow and plumbic acid, lithium-ion batteries are characterized by high energy density, little contamination, nontoxicity and positive rate capability due to the continuous development of corresponding technologies and increasingly lower cost of large-scale application in recent years. For example, lithium-ion batteries can achieve rapid charging and discharging like flywheel energy storage and play the supporting role in frequency control of power system; just like liquid flow batteries, lithium-ion batteries also embrace long-time energy storage for peak modulation of the power system, so as to relieve the operation pressure of power grid.

\subsubsection{Application case}

As shown in Table 1, plenty of large-scale energy storage power stations have been constructed domestically and overseas to be applied to diverse contexts like peak modulation, model study and auxiliary standby application [14]. By far, the largest flywheel energy storage power station in the world is the 20MW flywheel FM power station located in Hazle, Pennsylvania, U.S. With the use of $100 \mathrm{~kW}$ flywheel standalone integration, it fails to realize higher-capacity mature applications with the power higher than $100 \mathrm{MW}$. However, the application of large-scale lithium-ion batteries is relatively more mature, for instance, the Australian 100MW/129MWh lithium-ion battery energy storage power station has provided conventional modulation output, energy output, FM emergency output and other auxiliary services for power grid for many times since its establishment.

Table 1. Energy storage put into operation in recent years.

\begin{tabular}{|c|c|c|c|}
\hline \multicolumn{2}{|c|}{ Location and year } & Battery & FUN \\
\hline Jiangsu 101MW/202MWh & 2018 & li-ion & \multirow{2}{*}{ peak } \\
shift \\
Henan 9.6MW/4.8MWh & 2018 & li-ion & \\
\hline Liaoning 200MW/800MWh & - & flow & \\
\hline Hebei 20MW & 2011 & multi & \multirow{2}{*}{ demo } \\
\hline Shenzhen 4MW/16MWh & 2011 & li-ion & \\
\hline Australia 100MW/129MWh & 2017 & li-ion & spare \\
\hline Pennsylvania 20MW & 2014 & flywheel & \multirow{2}{*}{$\begin{array}{c}\text { ancill } \\
\text { ary }\end{array}$} \\
\hline New York 20MW & 2011 & flywheel & \multirow{2}{*}{}
\end{tabular}

\subsection{Requirements for high voltage DC operation}

Extra-high voltage DC is used as the main transmission way by global energy internet, which may result in great inactive power impact at commutation and even local voltage sag as well as DC commutation failure due to the weak AC and strong DC grid structure. For this, increasing large-scale energy storage is an effective approach to improve the inactive response capability and the voltage supporting ability by AC grid. Due to the high capacity of DC internet transmission, combined with the difficulty in real-time balance of power at the mains side and the load side, there will be voltage and power fluctuation for the transmission circuit caused by power imbalance. As a result, it will be hard to control the global energy internet tide. Therefore, configuring 
adequate energy storage is considered an effective way to realize power balance for the transmission circuit and solve the problem of voltage and power fluctuation.

Based on the above analysis, this paper attempts to study the features of extra-high voltage DC commutation failure. Large-scale lithium-ion battery technology is selected for modeling, and large-scale energy storage access simulation is achieved on PSCAD simulation platform.

\section{High-voltage DC commutation failures}

\subsection{Fault domain analysis}

As shown in Fig.3, a device that can be switched off is adopted for the VSC of flexible HVDC, which can avoid the problem of commutation failure. Despite of severe faults of the AC system on the receiving end, power can still be transmitted as long as there is voltage for the AC bus at the converter station.

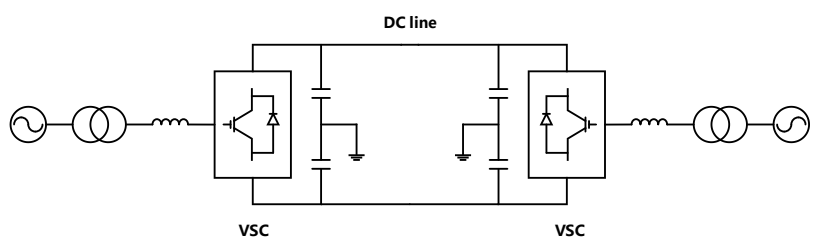

Fig. 3. Structure of the VSC of flexible HVDC.

Traditional converters at the HVDC power transmission receiving end are likely to cause commutation failure in case of faults for the AC system of the receiving end, which will result in the interruption of transmitting power. Generally, as long as the AC bus voltage at the inversion station falls sharply by over $10 \%$ due to faults for AC system, commutation failure of the inverter will occur, and it will be impossible for traditional DC system to transmit power before the recovery [15].

Fig. 4 is a monopole HVDC system with only one polar, and it usually takes the earth or seawater as return wires. Commutation failure is frequently seen on $\mathrm{AC}$ system at the receiving end whose fault point lies in the converter [16].

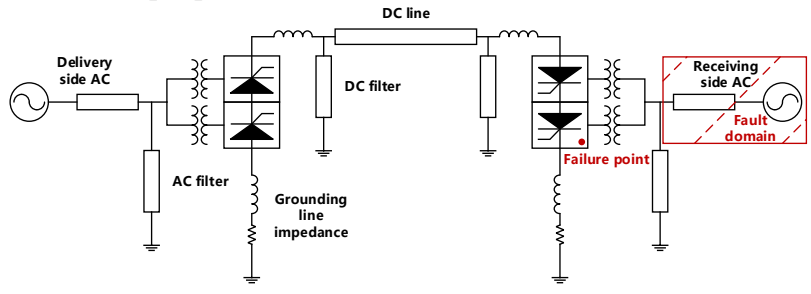

Fig. 4. Structure of a monopole HVDC with only one polar.

Fig.5 displays a bipolar HVDC system which contains a positive pole and a negative pole along with neutral ground. At steady-state operation, the current passing through each pole is the same with no current passing by the return wire. Both poles can operate independently. If one pole fails, the other will transmit power via the return wire. Compared with monopole HVDC, bipolar HVDC's ability to transmit power is doubled with relative small time-harmonic wave at normal operation. Similar to monopole HVDC, AC system at the receiving end is easy to cause commutation failure, and its fault point is located at two converters.

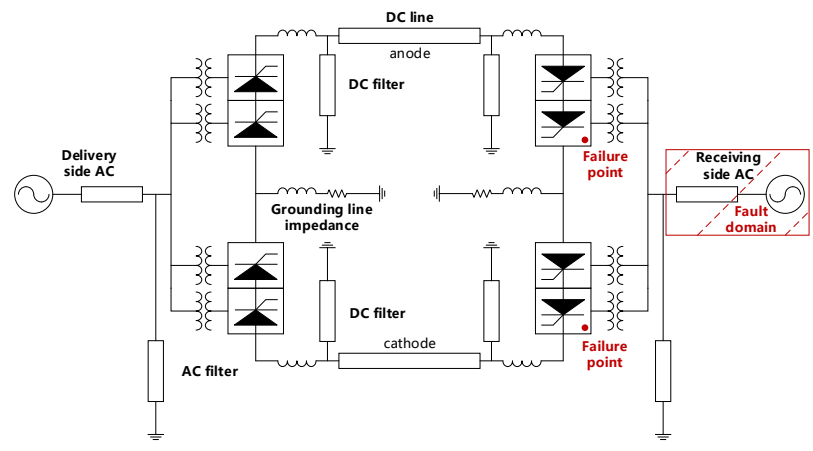

Fig. 5. Structure of a bipolar HVDC with two poles.

\subsection{Characteristics of commutation failure}

To explore the demand difference of energy storage with HVDC configuration in the event of commutation failure under two operation modes, a $+500 \mathrm{kV} / 1000 \mathrm{MW}$ monopole HVDC commutation failure model is constructed based on the PSCAD/EMTDC simulation platform. Since the turn-off recovery time of the thyristor element in HVDC is shorter than $400 \mu \mathrm{s}$ corresponding to the $7.2^{\circ}$ electrical angle under $50 \mathrm{HZ}$ frequency, the holding time of commutation failure can be defined below: the timing starts when the turn-off angle $\gamma$ is smaller than $7.2^{\circ}$ and ends when the turn-off angle $\gamma$ is recovered to $7.2^{\circ}$ without fluctuation for $20 \mathrm{~ms}$.

Set the simulation step size as $0.5 \mathrm{~s}$ and the fault triggering time of $0.3 \mathrm{~s}$, the simulation result of the inversion side of voltage can be shown in Fig.6. At around $0.2 \mathrm{~s}$ in Fig.7, the HVDC reaches the state of stable operation when the value $\gamma$ is approximately $18.5^{\circ}$

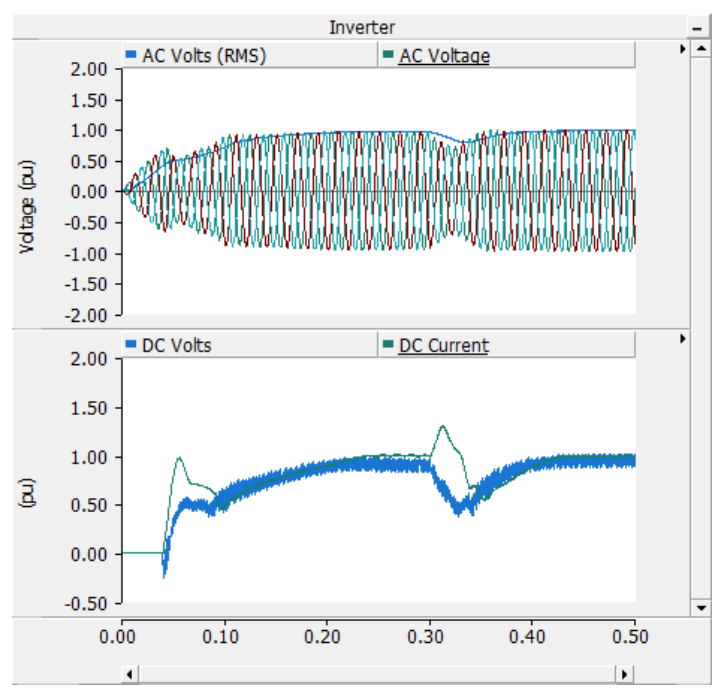

Fig. 6. The simulation result of the inversion side of voltage. 


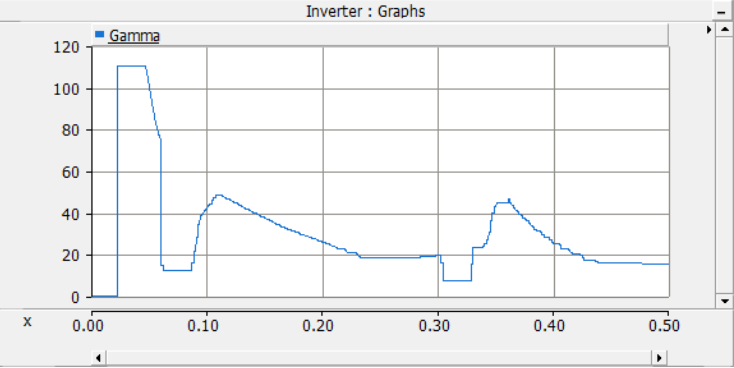

Fig. 7. The change of turn-off angle for a monopole HVDC.

According to the simulation results, commutation failure occurs to monopole HVDC at $0.3 \mathrm{~s}$ and the inversion side of voltage drops to about $67 \%$ of the normal value. At this time, the change of turn-off angle $\gamma$ is shown in Fig.6. At 0.304 s or around $304 \mathrm{~ms}$, the value is reduced to about $7.16^{\circ}$ or so, thus it can be determined that there is commutation failure. At $0.328 \mathrm{~s}$ or around $328 \mathrm{~ms}$, the value gradually rebounds to $20^{\circ}$ or above, and time of commutation failure lasts about $24 \mathrm{~ms}$ each time.

A $\pm 500 \mathrm{kV} / 2000 \mathrm{MW}$ bipolar HVDC commutation failure model is constructed based on the PSCAD/EMTDC simulation platform.

Set the simulation step size as $0.5 \mathrm{~s}$ and the fault triggering time of $0.3 \mathrm{~s}$, the simulation result of the inversion side of voltage can be shown in Fig.8. At around $0.2 \mathrm{~s}$ in Fig.9, the HVDC reaches the state of stable operation when the value $\gamma$ is approximately $31.8^{\circ}$.

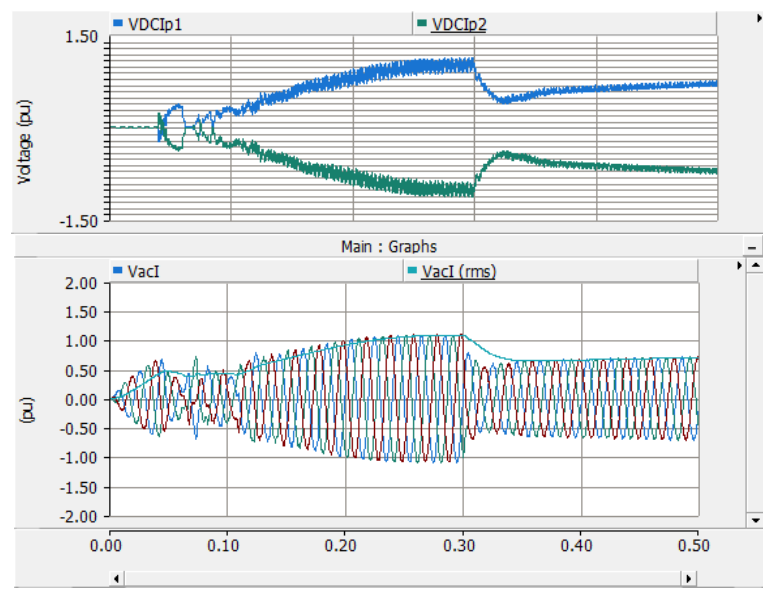

Fig. 8. The simulation result of the inversion side of voltage.

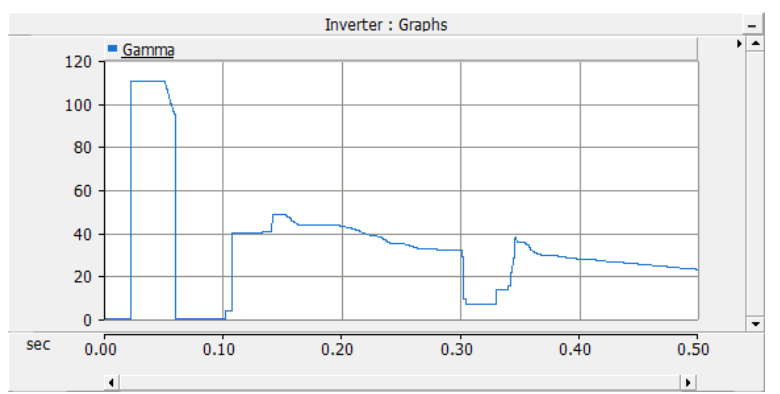

Fig. 9. The change of turn-off angle for a bipolar HVDC.
According to the simulation results, commutation failure occurs to bipolar HVDC at $0.3 \mathrm{~s}$ and the inversion side of voltage drops to about $67 \%$ of the normal value. At $0.305 \mathrm{~s}$ or around $305 \mathrm{~ms}$, the value is reduced to about $6.88^{\circ}$ or so, thus it can be determined that there is commutation failure. At $0.329 \mathrm{~s}$ or around $329 \mathrm{~ms}$, the value gradually rebounds to $13^{\circ}$ or above, and time of commutation failure lasts about $24 \mathrm{~ms}$ each time.

To sum up, the difference in operation modes for DC power transmission does not affect the configuration need of energy storage much, reasons of which are as follows: Firstly, when the voltage decline percentage is similar (always 67\% during the simulation), the minimum turnoff angle $\gamma$ will approach to a certain value, suggesting the demand for inactive power support is similar; secondly, the holding time of commutation failure is irrelevant with operation modes, which indicates the response time of the demand for energy storage configuration is basically the same (always $24 \mathrm{~ms}$ during the simulation).

\section{Model and simulation of storage}

The analytical process of energy storage configuration for HVDC commutation failure is shown in Fig. 10. First of all, determine the operation mode and fault type of HVDC. Bipolar HVDC contains more thyristor valves, which increases the number of commutation failure points. Determine whether the turn-off angle of the converter under fault mode is smaller than $7.2^{\circ}$. If it is larger than $7.2^{\circ}$, it will not be identified as commutation failure. If it is smaller than $7.2^{\circ}$, the holding time of each commutation failure will be from the initial timing to the holding time of over $20 \mathrm{~ms}$. Then determine whether there is continuous commutation failure for the converter under different fault types. The action time scope of the energy storage system, that is, the requirement for switch time, will be determined in this step. In case of no shutting, the commutation failure waveform will be improved by the energy storage system, which is mainly embodied in inactive power support. On the contrary, if the shutting does occur, the demanded switch time of the energy storage system will be longer, which will play a role of joint active and inactive support after DC shutting.

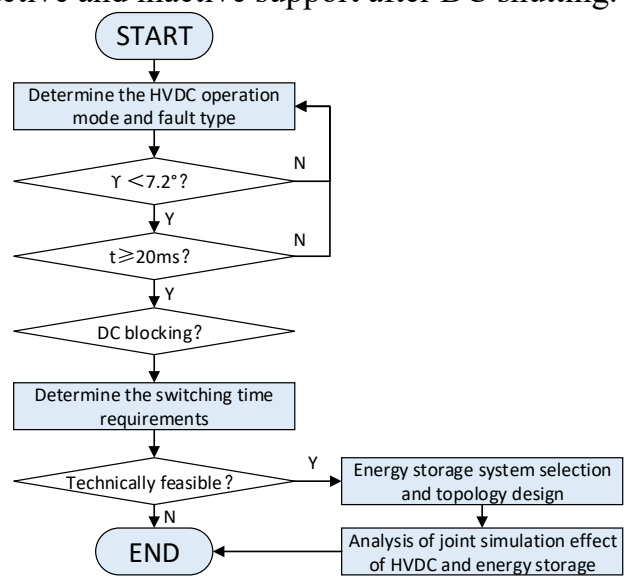

Fig. 10. The analytical process of energy storage configuration. 
A lithium-ion battery of energy storage power station model is constructed in the PSCAD/EMTDC simulation environment, the three-phase bridge conversion structure of which is shown in Fig. 11. Due to the high capacity of energy storage for supporting the stability of the power transmission system, the energy storage power station of lithium-ion batteries may be set to the level of $100 \mathrm{MW}$ in accordance with specific needs [17-19].

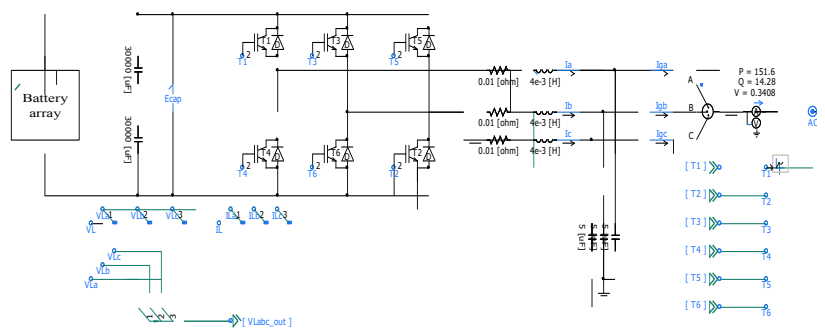

Fig. 11. The three-phase bridge conversion structure of storage.

As shown in Fig. 12, the capacity of the energy storage power station is set as 600MW. Based on the connection between two boosting transformers with the total capacity of 600MVA and the AC system at the receiving end, three-phase failure will be caused for the $\mathrm{AC}$ system at the HVDC receiving end under monopole operation, therefore, a power monitoring point is set at three positions, namely, the output side of energy storage power station, the low-voltage transformer side of inversion side and the bus collection and delivery side.

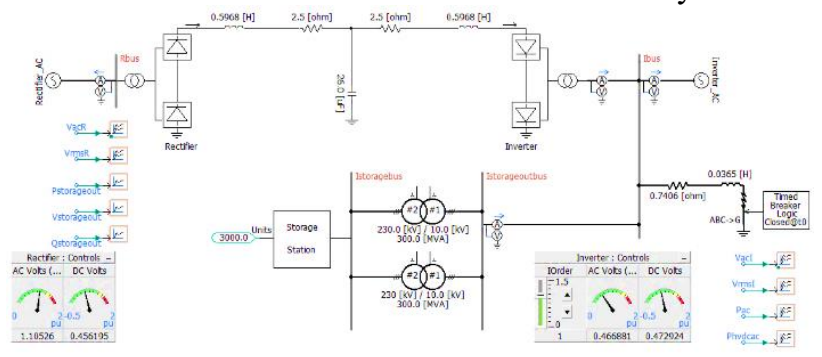

Fig. 12. Simulation topology of large-scale energy storage.

The time of commutation failure is set at $0.42 \mathrm{~s}$, with the negligence of communication delay. That is to say, the discharge output direction is executed by the energy storage system once the failure occurs, as shown in Fig. 13. The energy storage power station starts discharging at $0.42 \mathrm{~s}$, and it reaches the full-power constant output state in $100 \mathrm{~ms}$.

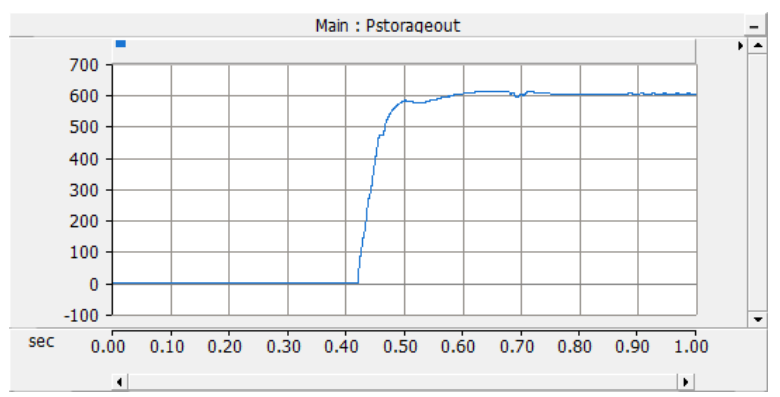

Fig. 13. Energy output of large-scale energy storage.

\section{Analysis of simulation results}

Under the simulation of fault conditions, severe commutation failure occurs to HVDC power transmission, which is accompanied by dramatic sudden decline of power. Regardless of the connection and operation of a $600 \mathrm{MW}$ energy storage power station, the power can eventually be stabilized at approximately $259 \mathrm{MW}$ as shown in Fig. 14.

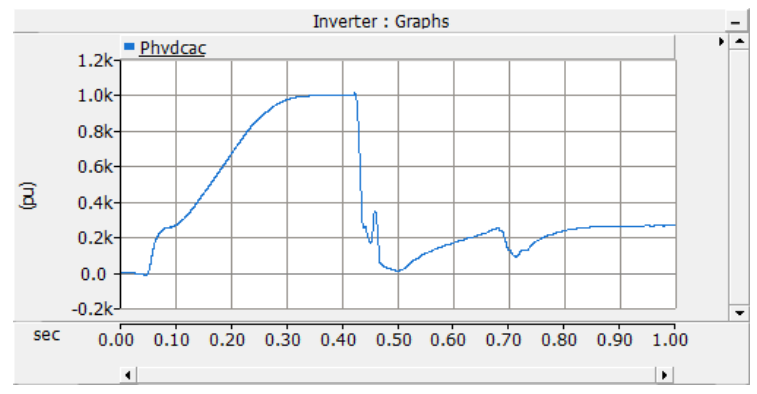

Fig. 14. Operation result without energy storage access.

Considering the connection and operation of a $600 \mathrm{MW}$ energy storage power station, active power can be lifted to around 795MW as shown in Fig.15.

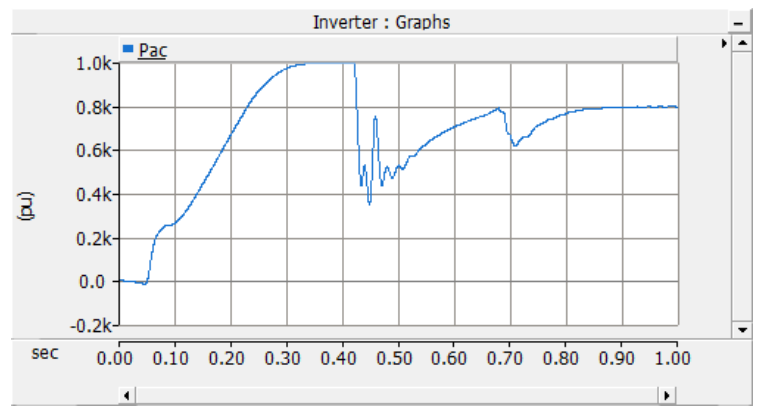

Fig. 15. Operation result with energy storage access.

As can be seen, the energy storage capacity configuration is positively correlated with the amplitude of the final active power. Theoretically speaking, with the negligence of the technical constraint of the energy storage system integration as well as the cost constraint, it is considered better if the capacity configuration of energy storage used for improving the stability of the power transmission system is larger.

\section{Conclusion}

1) The problem of commutation failure does not exist for flexible DC power transmission, which imposes no requirements for energy storage configuration arising from commutation failure. Only common HVDC power transmission may need to meet such requirements;

2) Monopole or bipolar operation by DC power transmission does not affect the configuration demand for energy storage significantly, the holding time of commutation failure (judging criteria: start timing when the turn-off angle $\gamma<7.2^{\circ}$, and stop when it rebounds to $7.2^{\circ}$ or above and holds for $20 \mathrm{~ms}$ ) is irrelevant to the operation mode, and the requirements for power support time of energy storage is basically consistent;

3) There is still technical bottleneck in super-large scale energy storage integration applicable to DC power 
transmission system configuration. Currently, only lithium-ion batteries and all-vanadium liquid flow batteries of energy storage power stations with the power higher than 100MW are under construction for modeling, while the flywheel energy storage integration technology with the power higher than $100 \mathrm{MW}$ is immature. Therefore, the lithium-ion battery technology is recognized as a relatively viable approach for supporting the power transmission system stability.

4) The holding time of each commutation failure by DC power transmission is usually around $30 \mathrm{~ms}$. Largescale lithium-ion batteries of energy storage power stations need about $100 \mathrm{~ms}$ from the static state to constant discharge (neglecting the communication delay of command receiving by the energy storage power station). In terms of the response speed, the inactive power support performance is not significantly superior to that of conventional inactive compensation devices.

5) After DC shutting resulting from continuous commutation failure by DC power transmission, active and inactive support can be provided for the operation of energy storage power stations, which can be determined by specific power vacancy values. As shown by the simulation results, the larger the capacity of energy storage configuration is, the more prominent the power support effect will be.

Thanks to the State Grid Co., Ltd.'s science and technology project "Research on key technologies for large-scale energy storage applications adapting to the global energy Internet" for supporting this paper.

\section{References}

1. OECD. Publishing, \& International Energy Agency. (2006). Energy technology perspectives: Scenarios and strategies to 2050. Organisation for Economic Co-operation and Development.

2. Zhenya, L. (2015). Global energy Internet. Beijing: China.

3. Jing $\mathrm{P}, \mathrm{Xu} \mathrm{G}$, Zhao B, et al. Large-scale Energy Storage Technology for Global Energy Internet[J]. Smart Grid, 2015, 3(6): 486-492.

4. Divya K C, Østergaard J. Battery energy storage technology for power systems-An overview[J]. Electric power systems research, 2009, 79(4): 511520.

5. Bingying S, Shuili Y, Zongqi L. Analysis on present application of megawatt-scale energy storage in frequency regulation and its enlightenment[J]. Automation of Electric Power Systems, 2017, 41(11): 8-16.

6. Yu H, Duan J, Du W, et al. China's energy storage industry: Develop status, existing problems and countermeasures[J]. Renewable and Sustainable Energy Reviews, 2017, 71: 767-784.

7. He G, Liang $\mathrm{Z}$, Lu $\mathrm{H}$, et al. Customer-side Distributed Energy Storage Application Considering Demand Management[C]//2018 International
Conference on Power System Technology (POWERCON). IEEE, 2018: 4089-4094.

8. Dunn B, Kamath H, Tarascon J M. Electrical energy storage for the grid: a battery of choices[J]. Science, 2011, 334(6058): 928-935.

9. Ibrahim H, Ilinca A, Perron J. Energy storage systems-Characteristics and comparisons[J]. Renewable and sustainable energy reviews, 2008, 12(5): 1221-1250.

10. Yuan X, Cheng S, Wen J. Prospects analysis of energy storage application in grid integration of large-scale wind power[J]. Dianli Xitong Zidonghua(Automation of Electric Power Systems), 2013, 37(1): 14-18.

11. Wentao H, Nengling T, Bin C , et al. DC System Fault Analysis and Protection Scheme Design for Megawatt Level Battery Energy Storage System[J]. Automation of Electric Power Systems, 2013, 37(1):76-83+167.

12. Schmidt O, Hawkes A, Gambhir A, et al. The future cost of electrical energy storage based on experience rates[J]. Nature Energy, 2017, 2(8): 17110.

13. Luo $\mathrm{X}$, Wang $\mathrm{J}$, Dooner $\mathrm{M}$, et al. Overview of current development in electrical energy storage technologies and the application potential in power system operation[J]. Applied energy, 2015, 137: 511536.

14. Amiryar M, Pullen K. A review of flywheel energy storage system technologies and their applications[J]. Applied Sciences, 2017, 7(3): 286.

15. Thio C V, Davies J B, Kent K L. Commutation failures in HVDC transmission systems[J]. IEEE Transactions on Power Delivery, 1996, 11(2): 946957.

16. Li S S, He X R, Ming Z Q, et al. Characteristics of capacitor commutated converter in the prevention of HVDC in commutation failure [J]. Power System Protection and Control, 2011, 18.

17. $\mathrm{Xu} \mathrm{L,} \mathrm{Chen} \mathrm{D.} \mathrm{Control} \mathrm{and} \mathrm{operation} \mathrm{of} \mathrm{a} \mathrm{DC}$ microgrid with variable generation and energy storage[J]. IEEE Transactions on Power Delivery, 2011, 26(4): 2513-2522.

18. Sparacino A R, Reed G F, Kerestes R J, et al. Survey of battery energy storage systems and modeling techniques[C]//2012 IEEE Power and Energy Society General Meeting. IEEE, 2012: 1-8.

19. Zhang Y, Guo L, Jia H, et al. An Energy Storage Control Method Based on State of Charge and Variable Filter Time Constant [J]. Automation of Electric Power Systems, 2012, 6. 